By: Terence A. Nile and Crystal A. Smith

T.A. Nile* and C.A. Smith, "Synthesis of Novel Platinum Complexes Showing Potential as Anti-Cancer Drugs," Inorganic and Nuclear Chemistry Letters, 15, 183 (1979).

Made available courtesy of Elsevier: http://www.elsevier.com/

****Reprinted with permission. No further reproduction is authorized without written permission from Elsevier. This version of the document is not the version of record. Figures and/or pictures may be missing from this format of the document. $* * *$

Article:

Many metal co-ordination complexes have been investigated as potential anti-cancer drugs with a rich diversity of effects and toxicity (1). One of the most successful is cis-diamminedichloroplatinum(II), which is an active anti-tumor agent at low concentration. Many complexes containing a variety of amines have been synthesized and tested, again with a wide range of effectiveness (1). We wish to report the synthesis of five new platinum complexes and the results of preliminary screening for potential anti-cancer activity.

The complexes, I - V , were synthesized by a modification of the procedure used to prepare cisdiamminedichloroplatinum(II) (2) by the reaction of the amine with potassium tetrachloroplatinate(II) in the presence of the amine hydrochloride, equation 1. The melting points and analytical data are included in Table 1 .

$$
\begin{aligned}
& \mathrm{K}_{2} \mathrm{PtCl}_{4}+2 \mathrm{RNH}_{2} \stackrel{\mathrm{RNH}_{3} \mathrm{Cl}}{\longrightarrow} \underset{\mathrm{CiS}}{\longrightarrow}\left[\mathrm{PtCl}_{2}\left(\mathrm{RNH}_{2}\right)_{2}\right]+2 \mathrm{KCl} \\
& \text { I } \quad \mathrm{R}=2-\mathrm{C}_{6} \mathrm{H}_{4} \mathrm{~F} \\
& \text { II } \quad \mathrm{R}=3-\mathrm{C}_{6} \mathrm{H}_{4} \mathrm{~F} \\
& \text { III } \quad \mathrm{R}=3-\mathrm{C}_{6} \mathrm{H}_{4} \mathrm{CF}_{3} \\
& \text { IV } \quad \mathrm{R}=2,4-\mathrm{C}_{6} \mathrm{H}_{3} \mathrm{~F}_{2} \\
& \mathrm{~V} \quad \mathrm{R}=\mathrm{CH}_{2}-2-\mathrm{C}_{6} \mathrm{H}_{4} \mathrm{~F}
\end{aligned}
$$

Preliminary screening of these complexes for potential anti-cancer potential by the National Institutes of Health indicate that complexes III - V show no activity against L-1210 lymphoid leukemia and that III shows no activity against P388 lymphocytic leukemia. I and II while showing no activity against L-1210 lymphoid leukemia were active against P388 lymphocytic leukemia. The maximum values of \% T/C (3) obtained against each tumor is included in Table 1. Complexes I and II are undergoing further testing to evaluate their potential anti-tumor activity.

\title{
Experimental
}

All complexes were prepared in a similar fashion. The preparation of I will be described as a typical example.

\section{Preparation of cis-bis-2-fluoroanilinedichloroplatinum(II)}

$3.30 \mathrm{~g}$ ( $30 \mathrm{mmol})$ of 2-fluoroaniline was placed in $125 \mathrm{ml}$ flask. $42 \mathrm{ml}$ of $1 \mathrm{M}(42 \mathrm{mmol})$ of dilute hydrochloric acid was added slowly, with stirring, via a medicine dropper. The mixture eventually became homogenous. A solution of $1.50 \mathrm{~g}(3.6 \mathrm{mmol})$ of potassium tetrachloroplatinate(II) in $10 \mathrm{ml}$ of water, which had been filtered, was added slowly to the stirred solution of anilinium hydrochloride. After about 2 minutes a precipitate formed. Stirring was continued for 30 minutes, when the solid was filtered off and washed with $3 \times 5 \mathrm{ml}$ of cold water and the $3 \times 5 \mathrm{ml}$ of hexane, and allowed to dry in air. A further $0.80 \mathrm{~g}(7.3 \mathrm{mmol}$.) of 2-fluoroaniline was added 
with vigorous stirring to the filtrante, which was stirred for 30 minutes and then placed in a refrigerator overnight. The yellow precipitate was filtered off and treated as before. A further $1.00 \mathrm{~g}(9.1 \mathrm{mmol}$.) of 2fluoroaniline was added with vigorous stirring to the filtrate, which was placed in the refrigerator as before, and a further crop of product removed by filtration and washed with water and hexane. Yield of yellow crystals of cis-his-2-fluoroanilinedicoloroplatinum(II) was $1.52 \mathrm{~g}(86 \%)$.

TABLE 1

Melting Points, Analytical and Test Data.

\begin{tabular}{|c|c|c|c|c|c|c|}
\hline Complex & Melting Point & Formula & \multicolumn{2}{|c|}{$\begin{array}{c}\text { Analytical Data } \\
\phi_{\mathrm{C}}(\text { calcd })\end{array}$} & \multicolumn{2}{|c|}{$\begin{array}{l}\text { Maximum Values } \\
\text { of } \% \text { w } / \mathrm{C}(\mathrm{a}) \\
{ }_{B}(\mathrm{c})\end{array}$} \\
\hline I & 254 & $\mathrm{Cl}_{2} \mathrm{H}_{2} \mathrm{~N}_{2} \mathrm{~F}_{2} \mathrm{Cl}_{2} \mathrm{Pt}$ & $29.35(29.52)$ & $2.22(2.48)$ & 115 & 148 \\
\hline II & $310-314$ & $\mathrm{C}_{2} \mathrm{H}_{2} \mathrm{~N}_{2} \mathrm{~F}_{2} \mathrm{Cl}_{2} \mathrm{Pt}$ & $28.69(29.52)$ & $2.33(2.48)$ & 114 & 167 \\
\hline III & $208-214$ & $\mathrm{C}_{14} \mathrm{H}_{2}{ }_{2} \mathrm{~N}_{2} \mathrm{~F}_{6} \mathrm{Cl}_{2} \mathrm{Pt}$ & $28.45(28.58)$ & $2.06(2.06)$ & 103 & 111 \\
\hline IV & 235 & $\mathrm{Cl}_{2} \mathrm{H}_{1} \mathrm{~N}_{2} \mathrm{~F}_{4} \mathrm{Cl}_{2} \mathrm{Pt}$ & $27.40(27.49)$ & $1.92(1.61)$ & 117 & (d) \\
\hline $\mathrm{V}$ & $227-228$ & $\mathrm{C}_{4_{4}} \mathrm{H}_{1}{ }_{6} \mathrm{~N}_{2} \mathrm{~F}_{2} \mathrm{Cl}_{2} \mathrm{Pt}$ & $32.51(32.57)$ & $2.95(3.12)$ & 100 & (d) \\
\hline
\end{tabular}

\section{References}

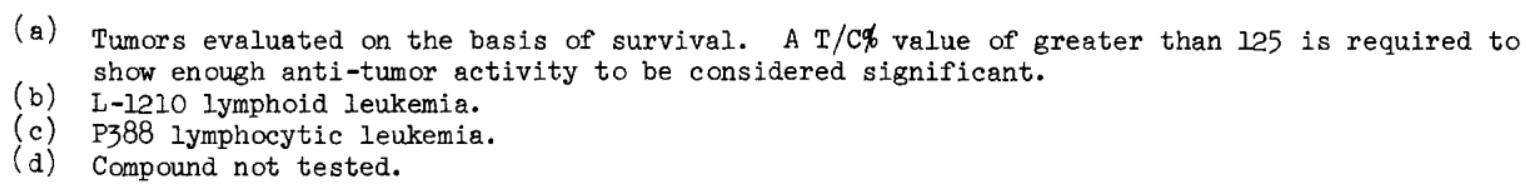

1. M. J. CLEARE and J. D. HOESCHEUE, Bioinorg. Chem., 2187 (1973).

2. G. B. KAUFFMAN and D. O. COWAN, Inorg. Syn., L 239 (1963).

3. $\mathrm{T} / \mathrm{C} \%$ is the ratio of test $(\mathrm{T})$ evaluation to control $(\mathrm{C})$ evaluation expressed as a percentage. 